\title{
Variational Iteration Method for Transverse Vibrations of the Elastic, Tensioned Beam
}

\author{
D. Dönmez Demir and E. Koca
}

\begin{abstract}
In this study, the dynamic behavior of an axially accelerating, elastic, tensioned beam are determined using variational iteration method. The axial velocity is considered as a constant mean velocity. Analytical solutions for these types of problems are exactly limited in some cases. Therefore, we need numerical methods to analyse such problems. For the solutions of linear or nonlinear problems, variational iteration method is introduced as an effective analytical approximation technique. It is concluded that proposed technique is an efficient tool for the analysis of specified problems for which an analytical solution does not exist.
\end{abstract}

Key words-Axially moving tensioned beam, dynamic behavior, variational iteration method.

\section{INTRODUCTION}

Axially moving beam-typed structures attract attention of many scientists because of technical importance and applications widely in the engineering. The many intensive studies focus on the dynamic analysis of an elastic or viscoelastic beam axially moving with variable or constant velocity. Firstly, Mote [1] investigated the natural frequencies of an axially moving elastic beam. Mote [2] considered axially moving materials in the early literature. Besides, Ulsoy [3] and Wickert [4] et al. presented the studies on this matter. More recently, Öz and Pakdemirli [5] investigated the dynamic response of an elastic, tensioned beam with a constant mean velocity varying harmonically. Wickert and Mote [6] analyzed free non-linear vibration of an axially moving, elastic, tensioned beam over the sub- and supercritical transport speed ranges. Öz et al. [7] presented the transition behavior from string to beam such that the flexural stiffness vanished in the governing equation in [5]. Chen and Zhao [8] considered free nonlinear transverse vibrations for axially moving beams with pinned or clamped ends. Pellicano and Zirilli [9] examined the dynamic behavior of an axially moving beam with vanishing flexural stiffness and weak non-linearities.

The dynamic behaviors of axially moving beams are investigated by various analytical and numerical approaches.

Manuscript received March 30, 2015; revised June 6, 2016.

Duygu Dönmez Demir and E. Koca are with the Celal Bayar University, Faculty of Art \& Sciences, Department of Mathematics, 45047, Manisa, Turkey (e-mail: duygu.donmez@ cbu.edu.tr).
Principal parametric resonances, combination resonances and stability boundaries for an axially accelerating, elastic, tensioned beam were discussed by Öz and Pakdemirli [5] via perturbation analysis. Öz [10] also used method of multiple time scales for the solution of an axially moving.

Euler-Bernoulli beam under simply supported and clamped boundary condition. Chen et al. [11] analysed transverse parametric vibration of an axially accelerating viscoelastic tensioned beam of which the material is defined by the Kelvin model by using Galerkin discretization. Chen $e t$ al. [12] introduced a modified finite difference approach to analyse transverse vibrations of an axially moving string. Čepon and Boltežar [13] applied Galerkin finite-element method to solve the governing equation of axially moving pre-tensioned beam with arbitrary support excitations. Wang et al. [14] used a collocation method to solve axially moving beam problems.

More recently, the some numerical approaches is alternative introduced to solve these type of problems. Lai $e t$ al. [15] applied Adomian decomposition method (ADM) for free vibration problems of Euler-Bernoulli beam under various supporting conditions. The natural frequencies and mode shapes of an Euler-Bernoulli beam under various supporting conditions were obtained by Liu et al. [16] via variational iteration method (VIM). Younesian et al. [17] examined the dynamic behavior of an elastic beam based on a nonlinear foundation by applying VIM.

In this study, the variational iteration method is applied to solve the Euler-Bernoulli beam problem [5]. The beam which is simply supported at both ends has a constant mean velocity. The more terms which can be obtained by VIM better represent the real behaviour of the system than other method.

\section{The EQUATION OF Motion}

The dimensionless equation of motion as given by Wickert [5], [6] is

$$
\ddot{u}+2 \dot{u}^{\prime} v+u^{\prime} \dot{v}+v_{f}^{2} u^{i v}+\left(v^{2}-1\right) u^{\prime \prime}=0
$$

where $u$ is the transverse displacement, $v$ is the axial velocity and $v_{f}^{2}$ is the dimensionless flexural stiffness which is a constant. The material particle of travelling beam experience local $\ddot{u}$, Coriolis $2 \dot{u}^{\prime} v$ and centripetal $v^{2} u^{\prime \prime}$ acceleration components. Since the velocity is assumed as constant in governing equation, the term $u^{\prime} \dot{v}$ vanishes [6]. Therefore, we get 


$$
\begin{gathered}
\ddot{u}+2 \dot{u}^{\prime} v+v_{f}^{2} u^{i v}+\left(v^{2}-1\right) u^{\prime \prime}=0 \\
u(0, t)=u(1, t)=0, \quad u^{\prime \prime}(0, t)=u^{\prime \prime}(1, t)=0
\end{gathered}
$$

The dot denotes differentiation with respect to time $t$ and the primes denote differentiation with respect to the spatial variable $x$.

\section{VARIATIONAL ITERATION METHOD}

In this part, the idea of variational iteration method is shortly introduced. Consider the general nonlinear differential equation given in the form

$$
L u(t)+N u(t)=g(t)
$$

where $L$ is a linear operator, $N$ is nonlinear operator, and $g(t)$ is a known function. By using the variational iteration method, a correction functional can be formed as

$$
u_{n+1}(t)=u_{n}(t)+\int_{0}^{t} \lambda\left(L u_{n}(\xi)+N \tilde{u}_{n}(\xi)-g(\xi)\right) d \xi
$$

where $\lambda$ is a general Lagrange multiplier, which can be determined optimally via variational theory; the subscript $n$ means the $n$th approximation; $\tilde{u}_{n}$ is a restricted variation and $\delta \tilde{u}_{n}=0$ [16].

\section{THE APPLICATION OF VIM}

The correction functional can be written as

$$
u_{n+1}(x, t)=u_{n}(x, t)+\int_{0}^{t} \lambda(s)\left\{\ddot{u}_{n}(x, s)+2 v \dot{\tilde{u}}_{n}^{\prime}(x, s)+v_{f}^{2} \tilde{u}_{n}^{i v}(x, s)+\left(v^{2}-1\right) \tilde{u}_{n}^{\prime \prime}(x, s)\right\} d s
$$

For the correction functional stable, if we apply the variational iteration method

$$
\begin{aligned}
\delta u_{n+1}(x, t) & =\delta u_{n}(x, t)+\delta \int_{0}^{t} \lambda(s)\left\{\ddot{u}_{n}(x, s)\right\} d s \\
= & \delta u_{n}(x, t)+\int_{0}^{t}\left\{\left[\frac{\partial^{2}}{\partial s^{2}} \lambda(s)\right] \delta u_{n}(x, s)\right\} d s-\left.\frac{\partial}{\partial s} \lambda(s) \delta u_{n}(x, s)\right|_{s=t}+\left.\lambda(s) \delta u_{n}^{\prime}(x, s)\right|_{s=t} \\
= & \left(1-\left.\frac{\partial}{\partial s} \lambda(s)\right|_{s=t}\right) \delta u_{n}(x, t)+\left.\lambda(s)\right|_{s=t} \delta u_{n}^{\prime}(x, t)+\int_{0}^{t}\left\{\left[\frac{\partial^{2}}{\partial s^{2}} \lambda(s)\right] \delta u_{n}(x, s)\right\} d s=0
\end{aligned}
$$

is obtained. Then, Euler-Lagrange equation is found as

$$
\lambda^{\prime \prime}(s)=0
$$

where initial condition is

$$
\left.\lambda(s)\right|_{s=t}=0,1-\left.\lambda^{\prime}(s)\right|_{s=t}=0 .
$$

If the problem is solved, we obtain

$$
\lambda(s)=s-t
$$

Substituting Lagrange multiplier into Eq. (6), the iteration formulation is obtained as

$u_{n+1}(x, t)=u_{n}(x, t)+\int_{0}^{t}(s-t)\left\{\ddot{u}_{n}(x, s)+2 v \ddot{u}_{n}^{\prime}(x, s)+v_{f}^{2} u_{n}^{i v}(x, s)+\left(v^{2}-1\right) u_{n}^{\prime \prime}(x, s)\right\} d s$

The initial approximation can be assumed as

$$
u_{0}(x, t)=X(x) \exp (i \omega t)
$$

For $n=0$, substituting Eq. (12) into Eq. (11), we get

$u_{1}(x, t)=X(x) \exp (i \omega t)+\int_{0}^{t}(s-t)\left\{\left[-\omega^{2} X(x)+2 i v \omega X^{\prime}+v_{f}^{2} X^{i v}+\left(v^{2}-1\right) X^{\prime \prime}\right] \exp (i \omega s)\right\} d s$

Result of the necessary process, we obtain the second term as

$u_{1}(x, t)=X \exp (i \omega t)+\left[v_{f}^{2} X^{i v}+\left(v^{2}-1\right) X^{\prime \prime}+2 i v \omega X^{\prime}-\omega^{2} X\right] \frac{(\exp (i \omega t)-i \omega t-1)}{\omega^{2}}$

The iteration can be continued in this manner. Thus, the general solution of Eq. (2) is

$$
u(x, t)=u_{0}(x, t)+u_{1}(x, t)+\cdots
$$

Since Eq. (12) holds Eq. (2), we obtain

$$
v_{f}^{2} X^{i v}(x)+\left(v^{2}-1\right) X^{\prime \prime}(x)+2 i v \omega X^{\prime}(x)-\omega^{2} X(x)=0
$$

where initial conditions are

$$
X(0)=X(1)=X^{\prime \prime}(0)=X^{\prime \prime}(1)=0 \text {. }
$$

Then, the solution of Eq. (16) is

$$
X(x)=c_{1} e^{i r_{1} x}+c_{2} e^{i r_{2} x}+c_{3} e^{i r_{3} x}+c_{4} e^{i r_{4} x}
$$

where $r_{n}(n=1, \ldots, 4)$ satisfies dispersive relation

$$
v_{f}^{2} r_{n}^{4}+\left(1-v^{2}\right) r_{n}^{2}-2 v \omega r_{n}-\omega^{2}=0, \quad \mathrm{n}=1, \ldots, 4
$$

Applying the simply supported boundary conditions, we obtain

$$
c_{1}+c_{2}+c_{3}+c_{4}=0
$$

$$
c_{1} r_{1}^{2}+c_{2} r_{2}^{2}+c_{3} r_{3}^{2}+c_{4} r_{4}^{2}=0
$$

$$
c_{1} e^{i r_{1}}+c_{2} e^{i r_{2}}+c_{3} e^{i r_{3}}+c_{4} e^{i r_{4}}=0
$$

$$
c_{1} r_{1}^{2} e^{i r_{1}}+c_{2} r_{2}^{2} e^{i r_{2}}+c_{3} r_{3}^{2} e^{i r_{3}}+c_{4} r_{4}^{2} e^{i r_{4}}=0
$$


The support condition is found by nontrivial solutions of Eqs. (20)-(23)

$$
\begin{aligned}
\left(e^{i\left(r_{1}+r_{2}\right)}+e^{i\left(r_{3}+r_{4}\right)}\right)\left(r_{1}^{2}-r_{2}^{2}\right)\left(r_{3}^{2}-r_{4}^{2}\right)+ & \left(e^{i\left(r_{1}+r_{3}\right)}+e^{i\left(r_{2}+r_{4}\right)}\right)\left(r_{2}^{2}-r_{4}^{2}\right)\left(r_{3}^{2}-r_{1}^{2}\right) \\
& +\left(e^{i\left(r_{2}+r_{3}\right)}+e^{i\left(r_{1}+r_{4}\right)}\right)\left(r_{1}^{2}-r_{4}^{2}\right)\left(r_{2}^{2}-r_{3}^{2}\right)=0
\end{aligned}
$$

$\omega$ and $r_{n}$ can be numerically calculated by using the dispersive relation and the support condition. The coefficients are obtained by elimination from Eqs. (20)-(23). Finally, Eq. (18) are

$$
\begin{aligned}
X(x)= & c_{1}\left\{e^{i i_{1} x}-\frac{\left(r_{4}^{2}-r_{1}^{2}\right)\left(e^{i r_{3}}-e^{i r_{1}}\right)}{\left(r_{4}^{2}-r_{2}^{2}\right)\left(e^{i r_{3}}-e^{i r_{2}}\right)} e^{i r_{2 n} x}-\frac{\left(r_{4}^{2}-r_{1}^{2}\right)\left(e^{i r_{2}}-e^{i r_{1}}\right)}{\left(r_{4}^{2}-r_{3}^{2}\right)\left(e^{i r_{2}}-e^{i r_{3}}\right)} e^{i r_{3} x}\right. \\
& \left.+\left[-1+\frac{\left(r_{4}^{2}-r_{1}^{2}\right)\left(e^{i r_{3}}-e^{i r_{1}}\right)}{\left(r_{4}^{2}-r_{2}^{2}\right)\left(e^{i r_{3}}-e^{i r_{2}}\right)}+\frac{\left(r_{4}^{2}-r_{1}^{2}\right)\left(e^{i r_{2}}-e^{i r_{1}}\right)}{\left(r_{4}^{2}-r_{3}^{2}\right)\left(e^{i r_{2}}-e^{i r_{3}}\right)}\right] e^{i r_{4} x}\right\}
\end{aligned}
$$

where $r_{1}, r_{2}, r_{3}, \mathrm{r}_{4}$ are constant [18]. Finally, the general solution is obtained by substituting Eqs. (25) into Eq. (15).

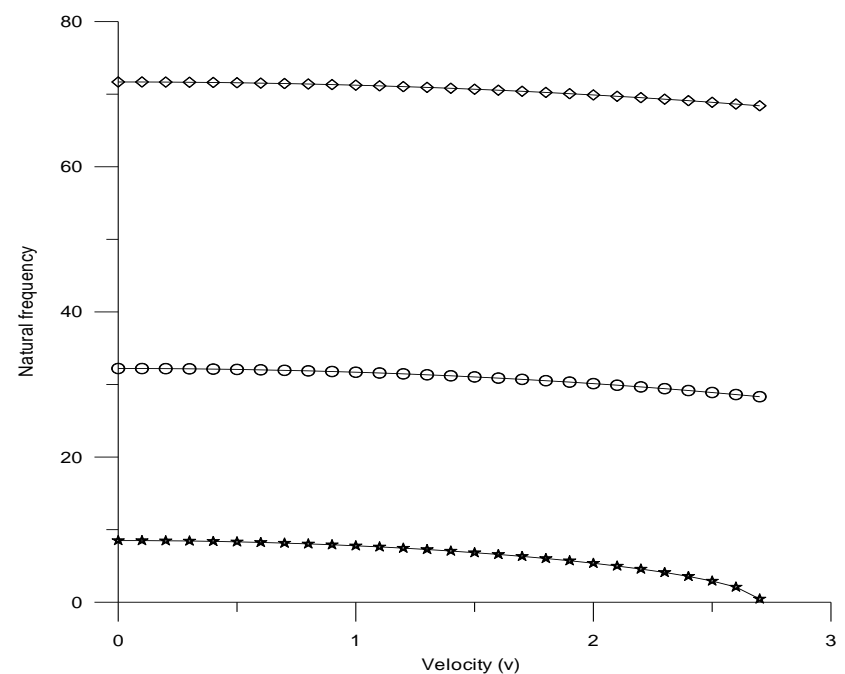

Fig. 1. Variation of natural frequency with dimensionless velocity for the different modes. Stars, circles and squares represent first, second and third mode natural frequencies, respectively $\left(v_{\mathrm{f}}=0.8\right)$.

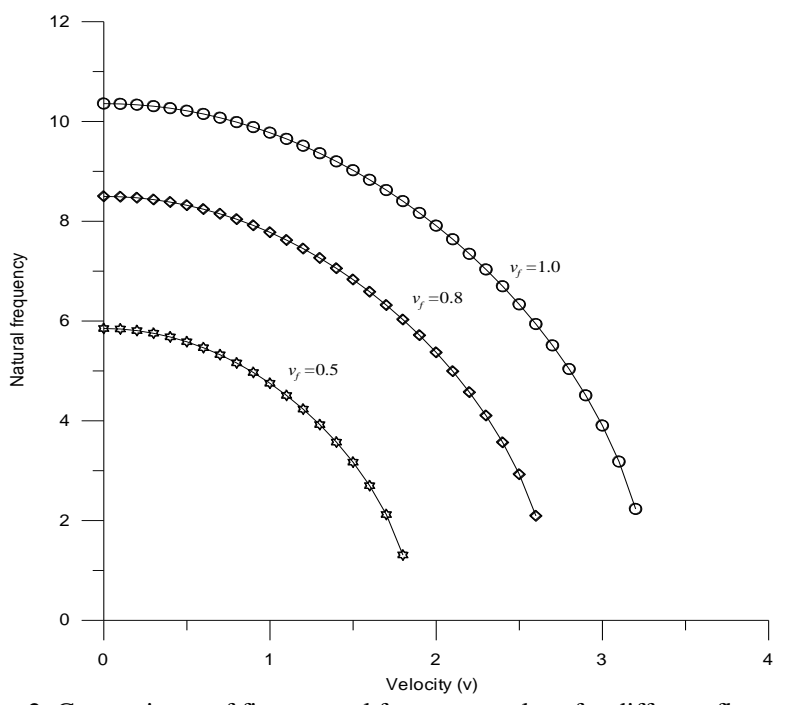

Fig. 2. Comparisons of first natural frequency values for different flexural stiffness for first mode.

\section{NUMERICAL RESULTS}

In this section, the graphs for the natural frequencies will be introduced. The natural frequencies are obtained from the solution of Eq. (19) and (24).

As seen, the dimensionless velocity at which the fundamental natural frequency close to zero is defined as the critical velocity and is approximately equal to the value of 2.7 as shown in Fig. 1. On the other hand, natural frequencies increase with increasing flexural stiffness (Fig. 2).

\section{ACKNOWLEDGMENT}

This work was supported by Celal Bayar University, Scientific Research Project Coordination Unit (Project number: 2015-103).

\section{REFERENCES}

[1] C. D. Mote, "A study of band saw vibrations," Journal of Franklin Institute, vol. 279, pp. 430-444, 1965.

[2] C. D. Mote, "Dynamic stability of axially moving materials," The Shock and Vibration Digest, vol. 4, pp. 2-11, 1972.

[3] A. G. Ulsoy, C. D. Mote, and R. Syzmani, "Principal developments in band saw vibration and stability research," Holz als Roh-und Werkstoff, vol. 36, pp. 273-280, 1978.

[4] J. A. Wickert and C. D. Mote, "Current research on the vibration and stability of axially moving materials," Shock and Vibration Digest, vol. 20, pp. 3-13, 1988.

[5] H. R. Öz and M. Pakdemirli, "Vibrations of an axially moving beam with time dependent velocity," Journal of Sound and Vibration, vol. 227, no. 2, pp. 239-257, 1999.

[6] J. A. Wickert, "Non-linear vibration of a travelling tensioned beam," International Journal of Nonlinear Mechanics, vol. 27, pp. 503-517, 1992.

[7] H. R. Öz, M. Pakdemirli, and E. Özkaya, "Transition behavior from string to beam for an axially accelerating material," Journal of Sound and Vibration, vol. 215, pp. 571-576, 1998.

[8] L. Q. Chen and W. J. Zhao, "A conserved quantity and the stability of axially moving nonlinear beams," Journal of Sound and Vibration, vol. 286, no. 3, pp. 663-668, 2005.

[9] F. Pellicano and F. Zirilli, "Boundary layers and non-linear vibrations in an axially moving beam," International Journal of Non-Linear Mechanics, vol. 33, pp. 691-711, 1998.

[10] H. R. Öz, "On the vibrations of an axially travelling beam on fixed supports with variable velocity," Journal of Sound and Vibration, vol. 239, no. 3, pp. 556-564, 2001.

[11] L. Q. Chen, X. D. Yang, and C. J. Cheng, "Dynamic stability of an axially accelerating viscoelastic beam," European Journal of Mechanics A-Solids, vol. 23, no. 4, pp. 659-666, 2004.

[12] L. Q. Chen, W. J. Zhao, and J. W. Zu, "Simulations of transverse vibrations of an axially moving string: A modified difference approach," Applied Mathematics and Computation, vol. 166, no. 3, pp. 596-607, 2005.

[13] G. Čepon and M. Boltežar, "Computing the dynamic response of an axially moving continuum," Journal of Sound and Vibration, vol. 300, no. 1-2, pp. 316-329, 2007.

[14] L. H. Wang, J. S. Chen, and H. Y. Hu, "Radial basis collocation method for dynamic analysis of axially moving beams," Interaction and Multiscale Mechanics, vol. 2, no. 4, pp. 333-352, 2009.

[15] H. Y. Lai, J. C. Hsu, and C. K. Chen, "An innovative eigenvalue problem solver for free vibration of Euler-Bernoulli beam by using the Adomian decomposition method," Computers and Mathematics with Applications, vol. 56, pp. 3204-3220, 2008.

[16] Y. Liu and C. S. Gurram, "The use of He's variational iteration method for obtaining the free vibration of an Euler-Bernoulli beam," Mathematical and Computer Modelling, vol. 50, no. 11-12, pp. 1545-1552, 2009.

[17] D. Younesian, Z. Saadatnia, and H. Askari, "Analytical solutions for free oscillations of beams on nonlinear elastic foundations using the variational iteration method," Journal of Theoretical and Applied Mechanics, vol. 50, no. 2, pp. 639-652, 2012.

[18] H. R. Öz, M. Pakdemirli, and H. Boyac1, "Non-linear vibrations and stability of an axially moving beam with time-dependent velocity," 
International Journal of Non-Linear Mechanics, vol. 36, pp. 107-115, 2001.

D. Dönmez Demir received her B.S. degree in mathematics at Celal Bayar University, Manisa / Turkey in 2004. She obtained her M.S. degree and Ph.D. degree at same university in 2008 and 2012, respectively. She worked as a research assistant from 2005 to 2013 at Celal Bayar University, the Faculty of Art \& Sciences, Department of Mathematics. Since 2013, she is working as an assistant professor at the same university. She is the author and coauthor of more than 28 articles, so far. Her research interests include partial and ordinary differential equations and their numerical solutions, fractional differential equations, dynamic analysis of continuous systems, linear and nonlinear vibrations. Duygu Dönmez Demir is a member in the editorial boards of four international journals. Additionally, she is a potentia reviewer in approximately thirteen international journals (SCI or not SCI).

E. Koca graduated from Celal Bayar University in 2013. He is a master student in same university. His research interests include ordinary and partial differential equations and their numerical solutions, linear and nonlinear vibrations. Moreover, he has 2 articles and 5 conference papers. 



\section{Power Machinery and Equipment}


